\title{
Determination of Safety Factors for Mango Fruit Paperboard Transport Crates under Refrigerated Conditions
}

\author{
B. Sadlowsky ${ }^{1}$, V. Köstner ${ }^{1,2}$, M. Mazur ${ }^{1}$, S. Thun ${ }^{3}$, P. Böröcz ${ }^{4}$ \\ ${ }^{1}$ BFSV Verpackungsinstitute Hamburg \\ Ulmenliet 20, 21033 Hamburg, Germany \\ ${ }^{2}$ University of Hamburg, Department of Wood Science \\ Mittelweg 177, 20148 Hamburg, Germany
}

${ }^{3}$ Hamburg University of Applied Sciences, Department of Nutrition and Home Economics

Ulmenliet 20, 21033 Hamburg, Germany

${ }^{4}$ Széchenyi István University, Department of Logistics and Forwarding

Egyetem sq. 1, 9026 Győr, Hungary

Phone: +36 96503400

e-mail: boroczp@sze.hu

Abstract: The use of corrugated board packaging is very popular in most industry sectors, but the food industry is one of the main consumers. Special requirements are placed on corrugated board in the food industry since the level of humidity necessary may be as high as $85-90 \%$ RH and this can greatly influence on the performance of the packaging. This influencing circumstance is taken into account in this paper when estimating a safety factor aimed at reducing risk. Knowing the safety factor can save transport and material costs, and can also prevent serious damage during the distribution of goods. The aim of this study is to determine the influence of humidity, pre-compression and load carriers on the stability of corrugated board mango fruit crates and thus to determine the safety factor. The results show that it is possible to calculate the safety factor by measuring realistic static stresses. Further 
researches into determining the dynamic stresses are required so as completing the calculation of the safety factor.

Keywords: safety factor, corrugated board, mango fruit crate

\section{Introduction}

Corrugated board packaging is the most popular packaging material in the distribution of industrial food products [1]. In addition to low weight and high stability, the corrugated board is environmentally friendly and very versatile in its function and use [2]. It will continue to be used in a number of industries in the future [1].

Packaging, which is made of corrugated board protects the food during transport and also has a product presentation function in the food industry [3]. A damaged package can decrease the sales value even if the product itself is free from defects [4]. Exposure to transport, handling and storing (THS) loads expose the packaging to stresses on a daily basis [5]. These stresses lead to deformation [6], compression and cracking of the packaging material, or to damages of product. To choose an appropriate packaging material requires knowledge of the conditions under which the food is transported. There is a particularly critical correlation between the quality of the corrugated board and the humidity of the environment or high-moisture foods [7][8]. Corrugated board loses its stability and structure, including detachment of the individual layers of paper, if the humidity level of the environment is too high or if the material comes into direct contact with water.

The investigation of single package under normal climatic conditions $\left(23{ }^{\circ} \mathrm{C}\right.$ and $50 \% \mathrm{RH}$ ) and any assessments derived from them with regard to the stability of similar corrugated boards under other climatic conditions may be inadequate. It is necessary to consider using a safety factor to reduce the risk of damage [8].

In the literature, there is a paper of Chonhenchob, in 2004, which dealt with the testing of various distribution packaging of mangos such as plastic crate, bamboo basket and corrugated box. The aim of that study was to compare the protection method of different types and to present an economic comparison of various packaging system [9]. Another paper of Chonhenchob evaluated the differences between corrugated boxes and plastic container. The results of that study indicated that proper shipping container and cushioning methods how to reduce bruising in mangoes [10]. Other papers analysed the effect of physical environment in distribution to mangoes such as transport vibration [11]. But the authors of this paper could not find any research on the compression strength of paperboard crates for mangoes with applicable safety factor with the aspect of refrigerated conditions. 
This study is concerned with determining safety factor for corrugated board mango fruit crates. Static stress conditions will be imitated by short-term BCT measurement of single crates and load units with high humidity under refrigerated conditions. Dynamic stresses are not considered in this investigation. The measurements are based on the climatic requirements of mango fruits $\left(11^{\circ} \mathrm{C}\right.$ and $\left.87 \% \mathrm{RH}\right)$.

\section{Methods}

\subsection{Materials}

The samples were corrugated board mango fruit crates (FEFCO 0422-V, DIN 55468-1:2015 2.50 BC flute) equipped with stacking noses. These were cut off the upper crates of a unit load for BCT measurements. The internal dimensions of the fruit crates were: $452 \times 383 \times 215$ [mm] (length $\times$ width $\times$ height).

\subsection{Loading units}

The same euro-pallets $(800 \times 1200 \mathrm{~mm})$ were used for all measurements, can be seen in Figure 1. Considering the outer dimensions of the crates $(490 \times 390 \times 220$ $\mathrm{mm})$ and potentially bulges $(10 \mathrm{~mm}), 4$ crates were packed at each layer. There was a remaining area of $200 \times 800 \mathrm{~mm}$, which meets an $83 \%$ rate of use. The crates were not modular. The loading unit was limited to a height of $1500 \mathrm{~mm}$, this way 6 crates were stacked. In total, there were 24 crates packed centrally on each pallet.

\subsection{Packaged goods}

The crates were filled with $12.5 \mathrm{~kg}$ cider apples to simulate a realistic punctual weight strain by mango fruits.

\subsection{Experiment setup}

The mechanical properties of the corrugated board used for the fruit crates were analysed by measuring BCT, ECT, bursting strength and puncture resistance. Furthermore, the paper quality and water resistance were tested to check wetstrength gluing.

The determination of short-term BCT values was conducted as described in DIN 55440-1:1991-11. The BCT values for investigating the mechanical properties of corrugated fibreboard were determined using single crates. This measurement was performed in 23/50 climate pairs only. Unit loads of fruit crates were measured in 23/50 and 11/87 climate pairs. The upper crates of unit loads with a pallet top and bottom were secured with a tension belt. 
The short-term BCT values for three different unit loads of fruit crates were determined in a 23/50 (Method A) and 11/87 (Method B) climate conditions. Taking the outer dimensions of the crates $(490 \times 390 \times 220 \mathrm{~mm})$ and any potential bulges $(10 \mathrm{~mm})$ into consideration, 24 crates were packed centrally on each pallet (Euro pallets $800 \times 1200 \mathrm{~mm}$ ). The crates were filled with $12.5 \mathrm{~kg}$ cider apples to simulate a realistic concentrated point load exerted by mango fruits. The 11/87 climate pairs were within the range of an optimum climate for mango fruits [12]. Both climates were compared, allowing for the influence of weight and load carriers on the crates. The unit loads were stressed using packed goods. The method was repeated without packed goods in a 23/50 climate pairs (Method C). The list and Figure 1 below illustrates the overall conditions described above.

(1) Load unit without carrier (Method A, B and C)

(2) Load unit with carrier on the bottom (Method A, B and C)

(3) Load unit with carrier on the bottom and top (Method A, B and C)

Method A: 23/50, Method B: 11/87, Method C: 23/50 without packed goods

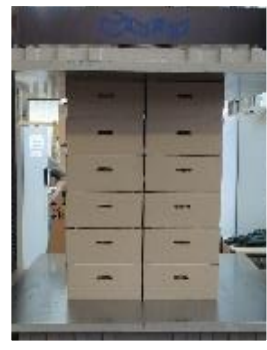

(1)

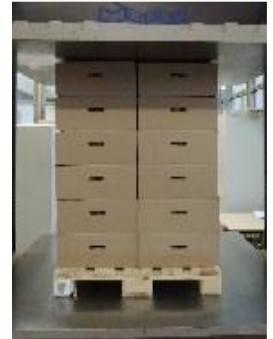

(2)

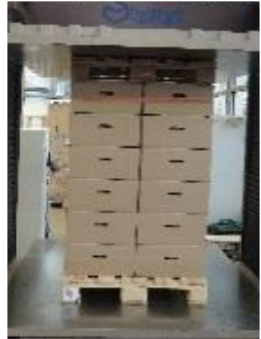

(3)

Figure 1. Test setup for fruit crates

The results of the mechanical properties of the fruit crates were averaged and are shown in Table 1 . The TAPPI test was performed on the packaging material since the single layers of paper did not detach after 24 hours of water influence.

Table 1. Averaged values for the mechanical properties of the fruit crates (FEFCO 0422-V)

\begin{tabular}{|c|c|c|c|c|}
\hline & $\begin{array}{c}\text { Bursting } \\
\text { strength }(\boldsymbol{k P a})\end{array}$ & $\begin{array}{c}\text { Puncturing } \\
\text { Energy }(\boldsymbol{J})\end{array}$ & $\begin{array}{c}\text { ECT } \\
(\boldsymbol{k N} / \boldsymbol{m})\end{array}$ & $\boldsymbol{B C T}(\boldsymbol{N})$ \\
\hline Avg. & 1433 & 9.2 & 11.0 & 7389 \\
\hline S & 58.4 & 0.3 & 0.3 & 629.7 \\
\hline
\end{tabular}




\begin{tabular}{|c|c|c|c|c|}
\hline $\mathrm{v}$ & 4.5 & 2.6 & 2.4 & 8.5 \\
\hline
\end{tabular}

Table 2 and 3 contains the results of BCT measurements for each unit load type and climate. All the unit loads that were air-conditioned in 11/87 climates and stressed with packed goods (1-3b) showed the lowest BCT values, while the unit loads without packed goods in $23 / 50$ climates $(1-3 \mathrm{c})$ displayed the highest. The other unit loads in the 23/50 climates, which were stressed with packed goods (1-3a) show lower results than ' $c$ ' but higher than ' $b$ '. At any rate, the results for ' $a$ ' and 'c' are similar considering the standard deviation but ' $c$ ' has higher displacement values than ' $a$ '. The standard deviation for $(1 \mathrm{c})$ is very high compared to all the other standard deviations.

Table 2. BCT values of unit loads without pallet (1); with pallet on the bottom (2); with pallet on the bottom and top (3)

\begin{tabular}{|c|c|c|c|c|c|}
\hline \multicolumn{6}{|c|}{ Method A (23/50 - with packed goods) } \\
\hline & $\mathrm{F}_{\max }(\mathrm{N})$ & Displacement (mm) & Avg. (N) & $\mathrm{S}(\mathrm{N})$ & $\mathrm{V}(\%)$ \\
\hline \multirow[t]{3}{*}{ (1) } & 19151 & 67 & 18997 & 810.7 & 4 \\
\hline & 20527 & 70 & & & \\
\hline & 19523 & 72 & & & \\
\hline \multirow[t]{3}{*}{ (2) } & 18674 & 70 & 19734 & 711.8 & 3 \\
\hline & 19919 & 67 & & & \\
\hline & 18397 & 66 & & & \\
\hline \multirow[t]{3}{*}{ (3) } & 20299 & 71 & 20249 & 417.8 & 2 \\
\hline & 19808 & 68 & & & \\
\hline & 20639 & 70 & & & \\
\hline \multicolumn{6}{|c|}{ Method B (11/87 - with packed goods) } \\
\hline & $\mathrm{F}_{\max }(\mathrm{N})$ & Displacement (mm) & Avg. $(\mathrm{N})$ & $\mathrm{S}(\mathrm{N})$ & $\mathrm{V}(\%)$ \\
\hline \multirow[t]{3}{*}{ (1) } & 10705 & 69 & 10634 & 367.1 & 4 \\
\hline & 10237 & 65 & & & \\
\hline & 10961 & 71 & & & \\
\hline \multirow[t]{3}{*}{ (2) } & 11642 & 69 & 11522 & 192.5 & 2 \\
\hline & 11624 & 66 & & & \\
\hline & 11300 & 67 & & & \\
\hline \multirow[t]{3}{*}{ (3) } & 11074 & 81 & 11038 & 180.7 & 2 \\
\hline & 11198 & 75 & & & \\
\hline & 10842 & 75 & & & \\
\hline
\end{tabular}


Table 3. BCT values of unit loads without pallet (1); with pallet on the bottom (2); with pallet on the bottom and top (3)

\begin{tabular}{|c|c|c|c|c|c|}
\hline \multicolumn{6}{|c|}{ Method C (23/50 - without packed goods) } \\
\hline & $\mathrm{F}_{\max }(\mathrm{N})$ & Displacement $(\mathrm{mm})$ & Avg. $(\mathrm{N})$ & $\mathrm{S}(\mathrm{N})$ & $\mathrm{V}(\%)$ \\
\hline \multirow[t]{3}{*}{ (1) } & 19317 & 95 & 19701 & 1834.9 & 9 \\
\hline & 18089 & 90 & & & \\
\hline & 21698 & 90 & & & \\
\hline \multirow[t]{3}{*}{ (2) } & 20841 & 88 & 20645 & 291.3 & 1 \\
\hline & 20783 & 88 & & & \\
\hline & 20310 & 90 & & & \\
\hline \multirow[t]{3}{*}{ (3) } & 21019 & 104 & 21035 & 206.9 & 1 \\
\hline & 20836 & 90 & & & \\
\hline & 21249 & 88 & & & \\
\hline
\end{tabular}

\section{Discussion}

\subsection{Effect of climate and load carrier}

Figure 3 shows the results of the BCT measurements for fruit crate unit loads in 23/50 (with and without packed goods) and 11/87 (with packed goods) climate overall.

There are small differences (3.9\%) between the results of unit loads that were measured in 23/50 climate pairs with and without packed goods. Crates that were stressed with packed goods (a) displayed a lower compression path $(69 \mathrm{~mm})$ compared to those without packed goods (c) $(91 \mathrm{~mm})$. This is caused by the precompression of the crates due to the packed goods.

The climate had a significant influence on the crush resistance of the crates that were air-conditioned in 11/87 climate pairs (b). The values of these crates were up to $45.5 \%$ lower than their counterparts (a) as a result of high humidity and precompression. It was estimated that the load carriers would exert additional stress on the units due to the alternately missing linear boards of the Euro pallet at the bottom (2) or due to additional weight on the top of the load unit (3). At any rate, there was a very small difference between experimental setup (2) and (3) in 23/50 climate pairs. 


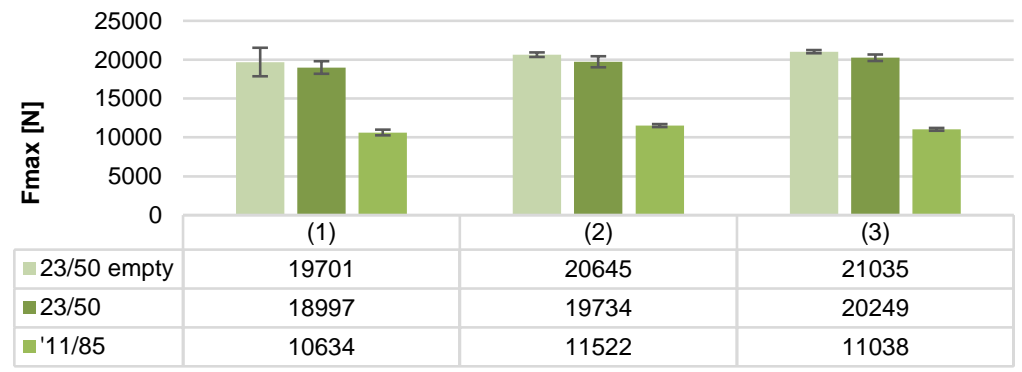

Figure 3. Summary for examined BCT force [N] of fruit crates units (Type FEFCO $0422-V)$

The upper pallet was placed precisely over the corners of the crates, which were the strongest part of the packaging. This protected the weaker parts of the crates against compression hazards. Without a pallet the force was distributed simultaneously over the corners as well as the sidewalls, which led to lower results among the stacking systems without a pallet (1).

Unexpectedly, the highest BCT values for unit loads that were air-conditioned in 11/87 climate pairs (Method B) were measured for a unit load with a carrier at the bottom (2). An additional carrier at the top stressed the unit (3). The humidity softened the material so that the compression force affected it more than crates that were air-conditioned in 23/50 climate pairs.

\subsection{Safety factor}

A safety factor of 3-5 was estimated in advance for the mango fruit crates in a standard climate. The safety factor based on this study takes account of static stresses on unit loads. Dynamic stresses were not considered. A value of $7389 \mathrm{~N}$ was determined by measuring the BCT of single fruit crates. Four fruit crates were packed on each layer. Thus, ultimately, a BCT of $7389 \mathrm{~N} \mathrm{x} 4$ layer $=29556 \mathrm{~N}$ should have been measured for a unit load. The highest BCT value was $21035 \mathrm{~N}$, which means a loss of $29 \%$ due to stacking the crates in a unit load. This shows that this calculation and estimating the safety factor based on experience is inadequate. Stacking of the individual crates also influences the BCT values and cannot be estimated.

To calculate a safety factor that takes account of realistic stresses on the packages, it is necessary to describe the THS stresses in as much detail as possible. Thus the safety factor must be calculated individually for each packaging and transport 
situation. The safety factor is usually estimated using a formula as provided by the VDA (German Association of the Automotive Industry) [13]:

$$
S=\frac{\text { loadability }(B C T, 23 / 50)}{\text { acceptable extra load }}
$$

Based on the VDA formula, a more detailed calculation is possible. A calculation for the safety factor can be formulated by considering the dynamic and static stresses:

$$
S \geq S_{\text {static }}+S_{\text {dynamic }}
$$

In this study, the static stress of corrugated board fruit crates was realistically imitated by measuring the BCT values of unit loads using apples as the packed goods in the optimum climate for mangoes. Taking these circumstances into account, the static safety factor can be defined as:

$$
S_{\text {stat }}=\frac{\text { loadability }(B C T, 23 / 50) \cdot \text { packaging on each layer }}{\text { loadability }\left(B C T_{L U}, \text { individual climate }\right)}
$$

Unit load $3 b$ is the most realistic stacking system in this study since it simulates the climate (11/87), weight and the stacking of a further unit load on top of it. The following calculation is an example of applying the formula defined above (Eq. 3) in relation to unit load $3 \mathrm{~b}$. The result of the calculation is as follows:

$$
S_{\text {stat }}=\frac{7389 \mathrm{~N} \cdot 4}{11038 \mathrm{~N}}=2.7
$$

Table 4. Calculated static safety factors for unit loads: (1) without pallet, (2) with pallet on the bottom, (3) with pallet on the bottom and top.

\begin{tabular}{|c|c|c|c|}
\hline & $\begin{array}{c}\text { Method } \boldsymbol{A} \\
\mathbf{2 3 / 5 0}\end{array}$ & $\begin{array}{c}\text { Method B } \\
\mathbf{1 1 / 8 7}\end{array}$ & $\begin{array}{c}\text { Method C } \\
\mathbf{2 3 / 5 0} \text { (empty) }\end{array}$ \\
\hline$(1)$ & 1.6 & 2.8 & 1.5 \\
\hline$(2)$ & 1.5 & 2.6 & 1.4 \\
\hline$(3)$ & 1.5 & 2.7 & 1.4 \\
\hline
\end{tabular}

A higher risk is expressed by a higher static safety factor as shown in the results above. The high humidity affects the packaging and therefore increases the values of the static safety factors for crates that were air-conditioned in 11/87 climate pairs. It is also necessary to determine the dynamic safety factor to complete the calculation and to properly define the safety factor. 


\section{Conclusion}

The results of the tested corrugated board mango fruit crates conclude the following general statements. Estimating the safety factor by measuring the BCT of single crates can be easily inadequate. It is necessary to determine the BCT under realistic conditions as shown in this study. The relative humidity, weight and stacking system have a significant influence on the performance of a packaging material. It is necessary to measure these effects individually for each packaging and stacking system. The static safety factor can be calculated based on static stress values. Further research is required to determine the dynamic stresses and thus to complete the presented calculation.

\section{Acknowledgement}

This work was supported by the project EFOP-3.6.1-16-2016-00017 of Széchenyi István University.

\section{References}

[1] Verband der Wellpappen-Industrie e.V., Die wichtigsten Zahlen für die Wellpappenindustrie (2015) [cited 2018-01-16]

URL http://wellpappenindustrie.de/data/04_Verband/05_Publikationen/03_ZahlenFakten/ZahlenFakt en-2015.pdf

[2] Bund Ökologische Lebensmittelwirtschaft, Nachhaltige Verpackung von BioLebensmitteln. Ein Leitfaden für Unternehmen, (2011) [cited 2016-02-14] URL http://herbaria.com/downloads/BOELW_Verpackungsleitfaden.pdf\#page=41

[3] R. Coles, M. Kirwan, Food and beverage packaging technology, 2nd Edition, Chichester, Ames: Wiley-Blackwell, 2011, p. 101.

[4] B. Steward, Verpackungsdesign, 1st Edition, London: Stiebner Verlag $\mathrm{GmbH}, 2008$, p. 173.

[5] H. Martin, Transport- und Lagerlogistik: Planung, Struktur, Steuerung und Kosten von Systemen der Intralogistik, 9th Edition, Hamburg: Springer Verlag, 2014, pp. 78-85. 
[6] P. Böröcz, Measurement and Analysis of Deformation Shapes on Corrugated Cardboard Logistical Boxes Under Static and Dynamic Compression, Acta Technica Jaurinensis 8 (4) (2015) pp. 320-329.

doi: 10.14513/actatechjaur.v8.n4.389

[7] V. Köstner, J. B. Ressel, B. Sadlowsky, P. Böröcz, Individual Test Rig for Measuring the Creep Behaviour of Corrugated Board for Packaging, Acta Technica Jaurinensis 10 (2) (2017) pp. 148-156.

doi: 10.14513/actatechjaur.v10.n2.445

[8] J-W. Rhim, Effect of Moisture Content on Tensile Properties of Paper-based Food Packaging Materials, Food Science and Biotechnology 19 (1) (2010) pp. 243-247.

doi: 10.1007/s10068-010-0034-x

[9] V. Chonhenchob, S. P. Singh, Testing and Comparison of Various Packages for Mango Distribution. Journal of Testing and Evaluation 32 (1) (2004) pp. 69-72.

doi: 10.1520/JTE1 1888

[10] V. Chonhenchob, S. P. Singh, A Comparison of Corrugated Boxes and Reusable Plastic Containers for Mango Distribution, Packaging Technology and Science 16 (6) (2003) pp. 231-237.

doi: $10.1002 /$ pts. 630

[11] K. Saha, S. P. Singh, J. Singh, Sensory Evaluation of Fresh Cut Mangos Packaged in Rigid Containers Subjected to Mechanical Abuse by Transport Vibration, Journal of Applied Packaging Research 5 (3) (2011) pp. 181-195.

[12] Gesamtverband der Deutschen Versicherungswirtschaft e. V. (GDV), Mangoes, GDV (2016) [cited 2016-02-22]

URL http://www.tis-gdv.de/tis/ware/obst/mango/mango.htm

[13] Verband der Automobilindustrie, Standardisierte Einwegverpackungen für Seecontainer-Anwendungen, VDA 4525 (2009) 